\title{
Макєঠovıкá
}

Tó 35 (2006)

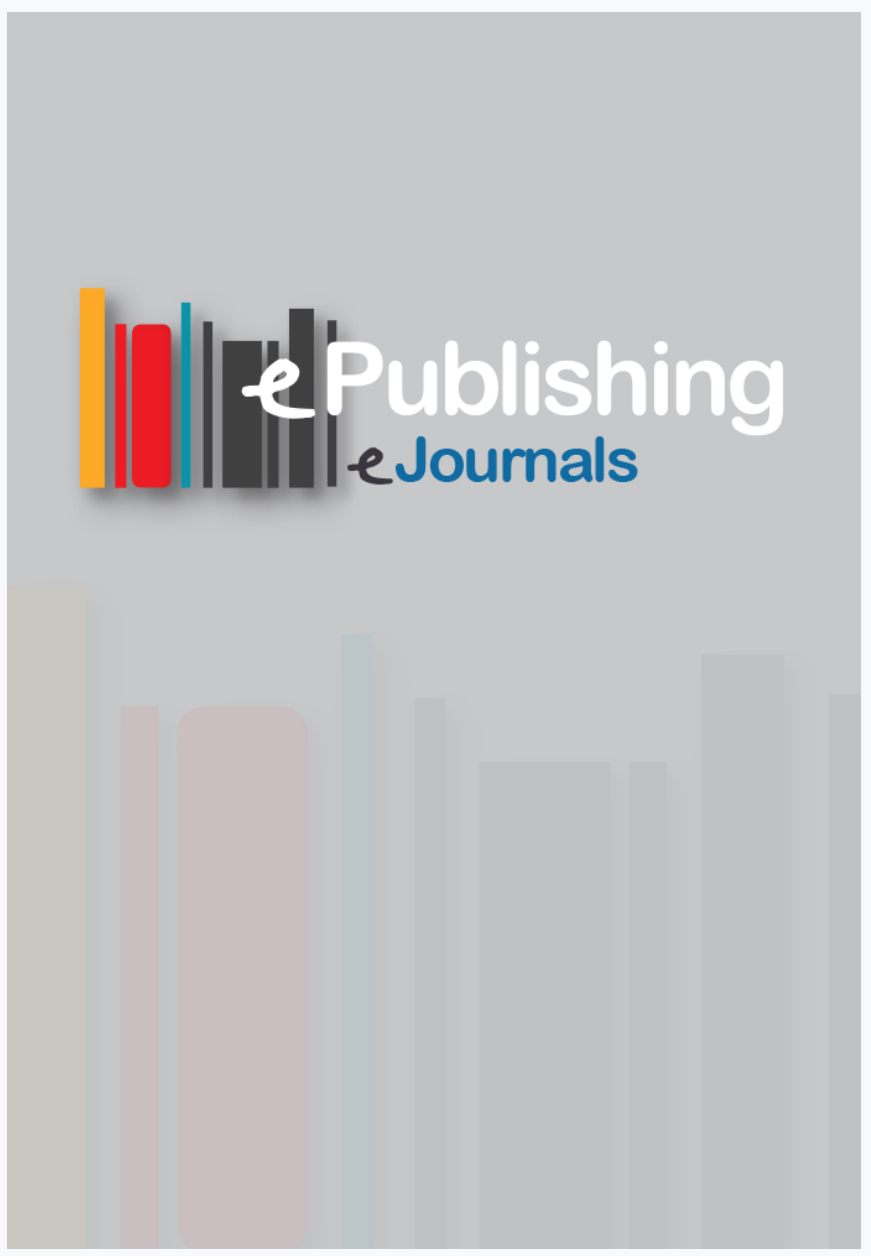

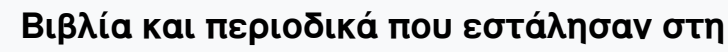

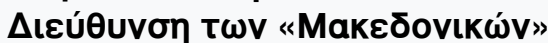

\section{Makedonika Makedonika}

doi: $10.12681 /$ makedonika.21

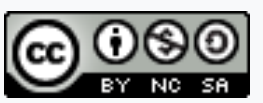

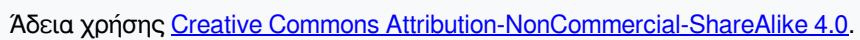

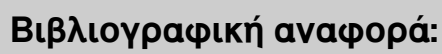

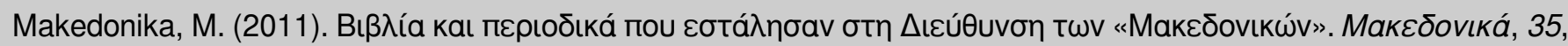
311-314. https://doi.org/10.12681/makedonika.21 


\title{
BIB $\Lambda$ IA KAI ПEPIO $\triangle$ IKA \\ ПOY E $\Sigma T A \Lambda H \Sigma$ AN $\Sigma$ TH $\Delta$ IEY $\Theta Y N \Sigma H$ T $\Omega N$ «MAKE $\Delta O N I K \Omega N »$
}

\author{
A' BIB $\Lambda I A$
}

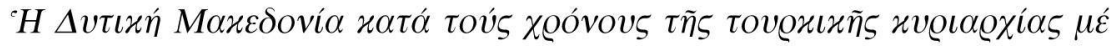

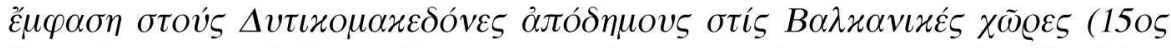

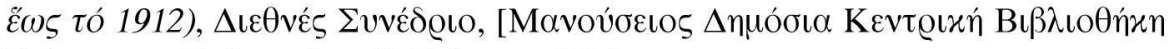

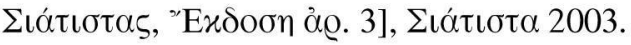

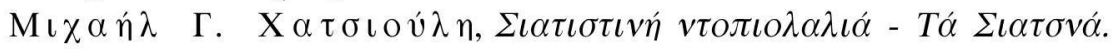

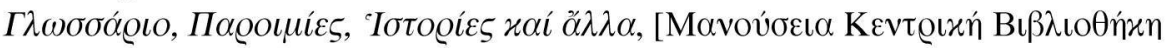

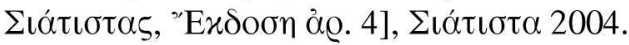

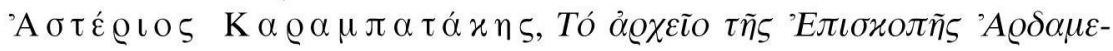

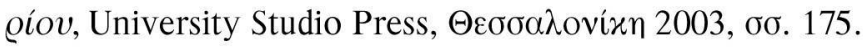

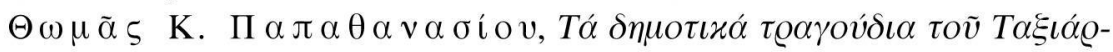

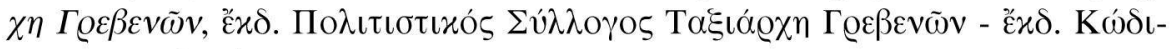

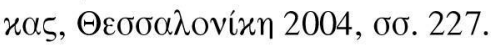

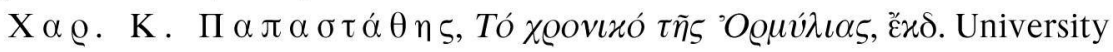

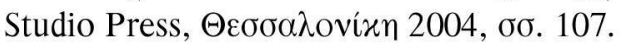

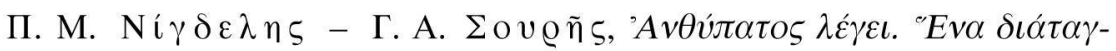

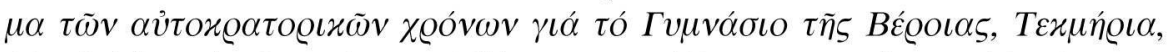

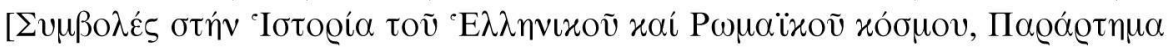

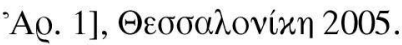

Lyudmil Ferdinandov Vagalinski, Burnished pottery from the first century to the beginning of the seventh century $A D$ from the region south

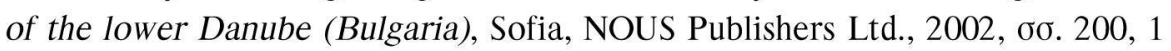

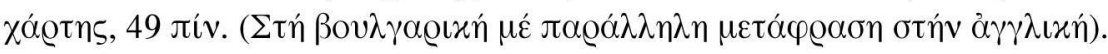

\section{В' ПЕPIOAIKA}

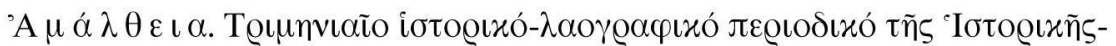

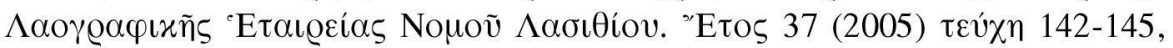

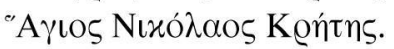

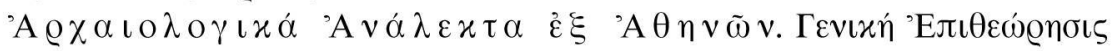

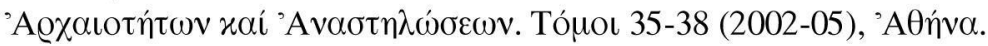

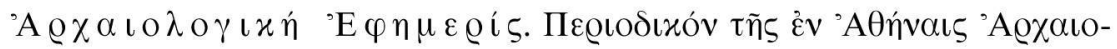

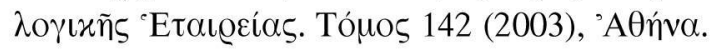




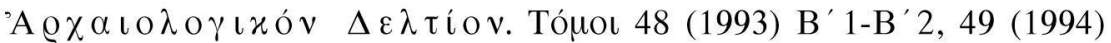
B' 1-B' 2, 49-50 (1994-95) A', 50 (1995) B' 1-B'2, 51 (1996) B' 1-B'2, 51-52 (1996-97) A', 53 (1998) A', B1-B3, 54 (1999) A', B1-B3, 55 (2000) A', 'A $\theta \dot{n} v \alpha$.

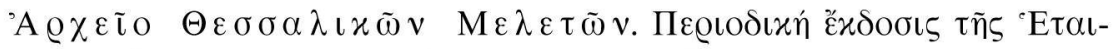

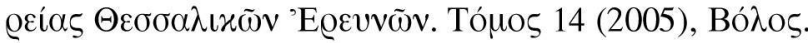

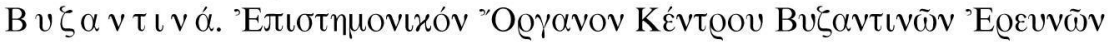

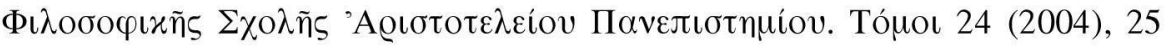

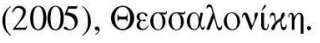

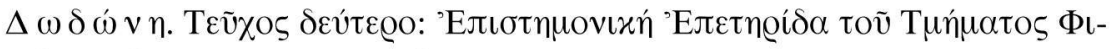

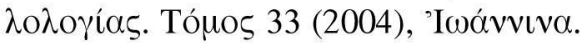

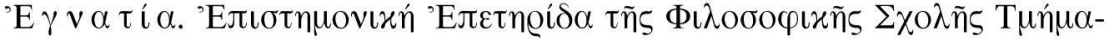

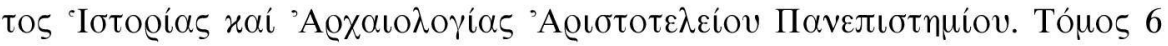

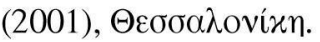

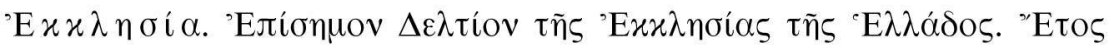

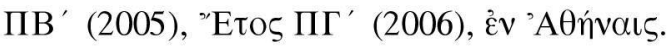

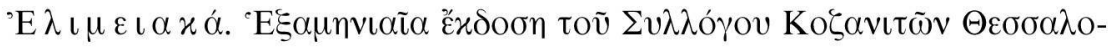

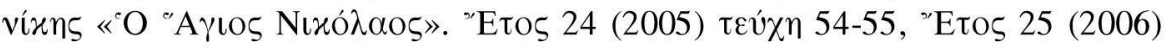

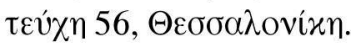

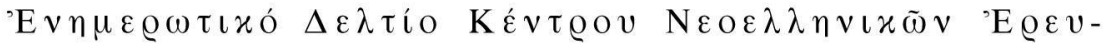

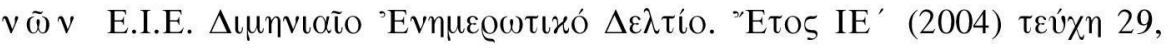
'A $\theta$ ńva.

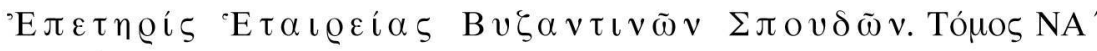

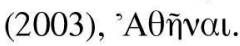

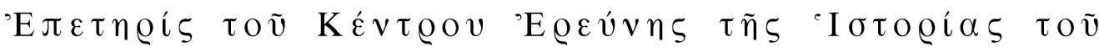

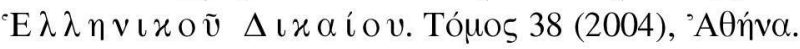

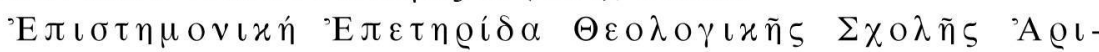

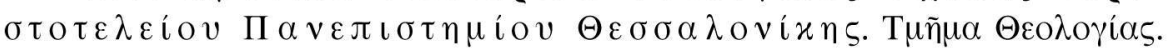

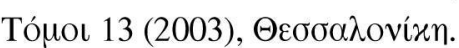

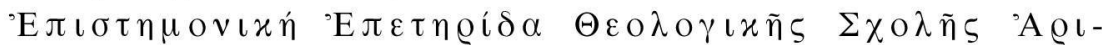

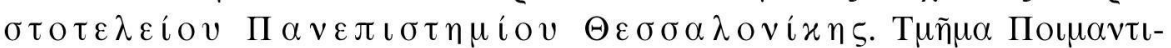

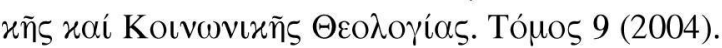

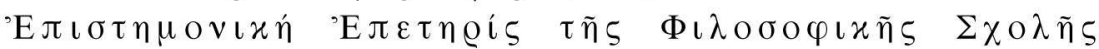
$\tau$ о $\tilde{v} \Pi \alpha v \varepsilon \pi \iota \sigma \tau \eta \mu$ ív 'A $\theta \eta v \tilde{\omega} v$. Tó $\mu$ ol $\Lambda \mathrm{E}^{\prime}$ ' (2003-2004), $\Lambda \Sigma \mathrm{T}^{\prime}$ (20042005), 'A $A \eta \dot{\eta} v \alpha$.

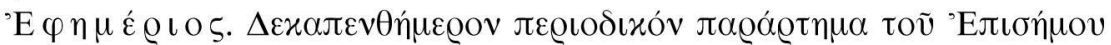

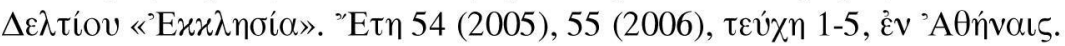

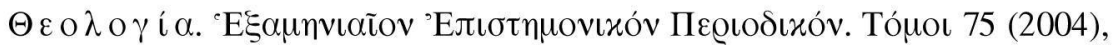
76 (2005), غ̇v 'A

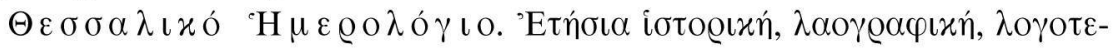




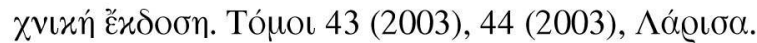

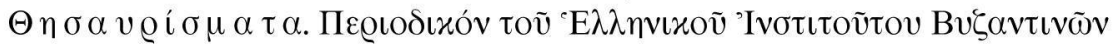

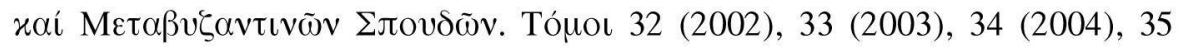
(2005), Bevetía.

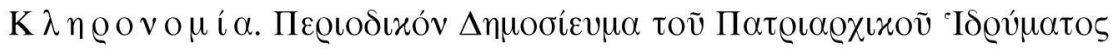

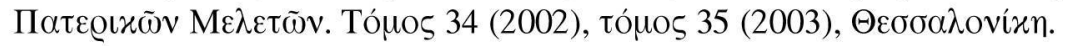

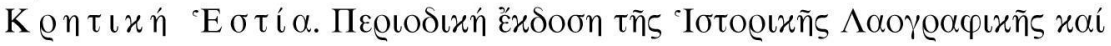

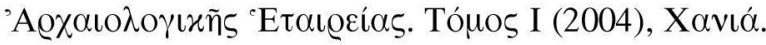

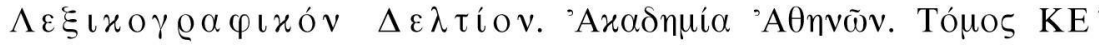
(2004-05), 'A $A$ ń $v$.

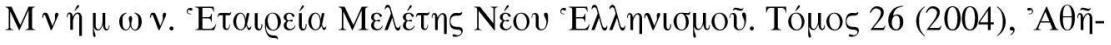
val.

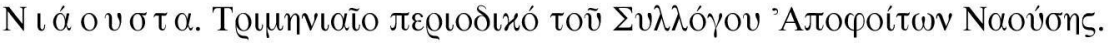

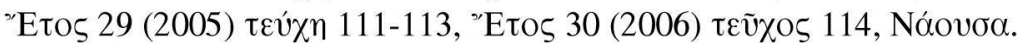

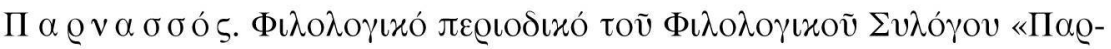

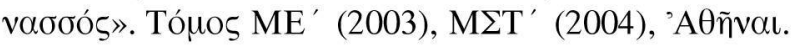

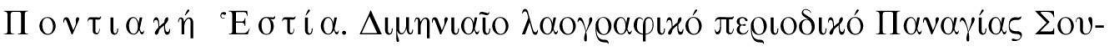

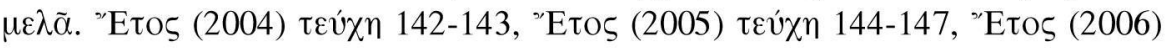

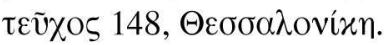

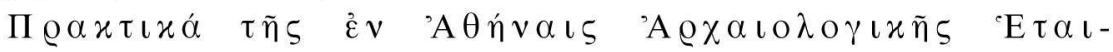

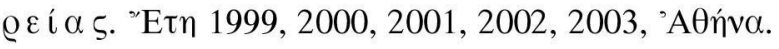

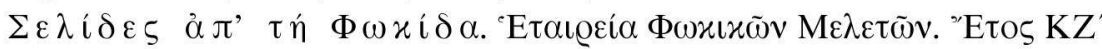

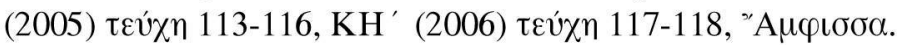

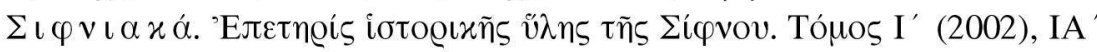

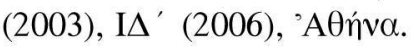

Analecta Bollandiana. Revue critique d'hagiographie trimestrielle. Tome 122 (2004) Fasc. 1-2, Tome 123 (2005) Fasc. 1-2, Tome 124 (2006) Fasc. 1-2, Bruxelles.

The Annual of the British School at Athens. Year No 98 (2003), No 99 (2004), London.

A pu 1 u m. Acta Musei Apulensis: Arheologie, Istorie, Etnografie. Vol. 39 (2002), Vol. 40 (2003), Vol. 41 (2004), Vol. 42 (2005), Alba Iulia.

The Bodleian Library Record. Vol. XVIII (2003-) No 2-6, Oxford.

Bulgarian Historical Review. Research Quarterly Organ of the United Centre for History at the Bulgarian Academy of Sciences. Year 32

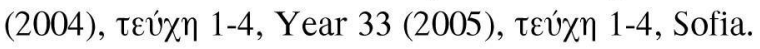


Byzantine and Modern Greek Studies. Centre for Byzantine, Ottoman and Modern Greek Studies, University of Birmingham. Vol. 29 (2005), Vol. 30 (2006).

Études Balkaniques. Académie Bulgare des Sciences. Institut d'Études Balkaniques. Vol. 40 (2004) no 2-4, Vol. 41 (2005) no 1-4, Sofia.

Hesperia. Journal of the American School of Classical Studies at Athens. Vol. 73 (2004) no 1-2, Vol. 74 (2005) no 2-4, Vol. 75 (2006) no 1, Athens.

Historical Abstracts. Bibliography of the World's Historical Literature. Vol. 55 (2004), Vol. 56 (2005), Santa Barbara, California.

Journal of Hellenic Studies. Vol. 124 (2004), Vol. 125 (2005), London.

Makedonski Pregled. Spisanie za Nauka, literatura i Obštestven život. Godina 27 (2004) kn 1-4, godina 28 (2005) kn 1-4. Makedonskijat Naucen Institut, Sofija.

Mélanges de l'École Française de Rome (MEFRA). Tome 116 (2004), Tome 117 (2005), Rome.

Mittheilungen des Deutschen Archäologischen Instituts Athenische Abteilung. Band 117 (2002), Band 118 (2003), Band 119 (2004), Berlin.

Prilozi Povijesti Unjetnosti u Dalmaciji. Državna Uprava za Zaštitu Kulture i Prirodne Baštine Glavno Povjerenstvo u Splitu. Tomes 39 (2001-02), 40 (2003-04), Split.

Revue des Études Byzantines. Institut Français d'Études Byzantines, Tome 62 (2004), Paris.

Revue des Études Grecques. Publication trimestrielle de l'Association pour l'Encouragement des Études Grecques. Tome 118 (2005), Paris.

Revue des Études Sud-Est Européennes. Publié par l'Académie des Sciences Sociales et politiques. Institut d'Études Sud-Est Européennes. Tome 40 (2002) no 1-4, Tome 41 (2003) no 1-4, Tome 42 (2005) no 14, Tome 43 (2006) no 1-4, Bucuresti.

Rivista di Archeologia. Publicazione annuale diretta da Gustavo Traversari. Università degli studi. Anno XXVII (2003), XXVIII (2004), Venezia.

Vestnik Drevnej Istori i. Rossijskaja Akademija Nauk. Institut Vseobsej Istorii. Vol. (2004) no. 2-3, Vol. (2005) no 1-4, Moskva. 